\title{
Develop the Primary Direction Based on the 3E's of Sustainability For Different Cities' Smart Growth
}

\author{
Jixian Wang \\ School of North China Electric Power University, Baoding 071000, China \\ 939189710@qq.com
}

\begin{abstract}
At present, when resources are limited, in order to make more efficient use of resources, we need to prioritize the primary sustainable development goals according to the characteristics of different cities .With the rapid development of urbanization and urban economy in China, cities are experiencing the rapid expansion of the scale of space. Therefore, how to choose a reasonable urban spatial expansion strategy in the process of rapid urbanization makes it not particularly affect the urban social and economic development and environmental development, but also to achieve the full use of land is particularly urgent, In order to achieve sustainable development planning goals, many cities are implementing smart growth plans. We use the 3E's objective of sustainable development as the basis for analysis. We select two cities as the research object, we propose the corresponding solution according to the 3E's target, Consider the characteristics of different urban development, We set up a model, and finally in accordance with the priorities of different measures to develop a more efficient development plan, in this way, we can provides a simple idea for the city to build a smart construction.
\end{abstract}

Keywords: Urban smart growth, Sustainable Cities, the 3E’s of sustainability.

\section{Introduction}

Since the 20th century the 60's, with the deepening of urban suburbanization, the review of 'Urban Sprawl'has attracted more and more attention from the public.'Urban Sprawl'mainly refers to the urban space of low-density expansion. In this process involved agricultural land ,the transformation of open space to construction land, and with a series of economic, social and environmental problems 。 Cities are the main bearers of the future population and economy, representing the occupation of land, energy consumption, resulting in the main environmental pressure. It is estimated that by 2050, the urban population will reach $66 \%$ of the world's total population.

In China, the use of land resources is limited, especially the tightening of cultivated land resources, the acceleration of urbanization process, the rapid growth of urban economy conditions, the choice of smart urban space expansion model is a realistic requirement, but also the requirements of the development of the times.

Smart growth is a comprehensive strategy for urban development that covers multiple levels. Therefore, the smart growth for urban space expansion provides a new research perspective. So the city's sustainable construction is becoming more and more important $[1,4,5]$

\section{Model assumptions}

- Ignore the impacts of the extreme disasters.

- Ignore the impacts of the migration of population

- Two cities that we need to choose which both in different continents(city A,B) 


\section{Data collection of cities}

Table 1 . the data of the factor of City A and B

\begin{tabular}{|c|c|c|c|c|c|c|c|c|c|c|}
\hline Years & \multicolumn{2}{|c|}{2011} & \multicolumn{2}{|c|}{2012} & \multicolumn{2}{|c|}{2013} & \multicolumn{2}{|c|}{2014} & \multicolumn{2}{|c|}{2015} \\
\hline City & A & B & A & B & $\mathrm{A}$ & B & A & B & A & B \\
\hline$\left(x_{1}\right)$ Per capita GDP & 48774.8 & 43306.5 & 49481.2 & 44261.9 & 49941.5 & 43554.21 & 50727.8 & 44877.55 & 51638.1 & 45408.32 \\
\hline $\begin{array}{l}\left(x_{2}\right) \text { Unit GDP energy } \\
\text { consumption }\end{array}$ & 0.42 & 0.38 & 0.41 & 0.36 & 0.39 & 0.35 & 0.38 & 0.34 & 0.38 & 0.33 \\
\hline$\left(x_{3}\right)$ Per capita green area & 35.2 & 41.2 & 36.7 & 41.5 & 38.5 & 41.6 & 39.4 & 41.6 & 39.2 & 42.3 \\
\hline$\left(x_{4}\right)$ Gini Coefficient & 0.47 & 0.35 & 0.45 & 0.33 & 0.43 & 0.35 & 0.42 & 0.34 & 0.41 & 0.36 \\
\hline$\left(x_{5}\right)$ unemployment rate & 9 & 6.6 & 8.2 & 6.8 & 7.4 & 7.3 & 6.7 & 7.2 & 5.5 & 7.5 \\
\hline $\begin{array}{l}\left(x_{6}\right) \text { The total retail sales of } \\
\text { social }\end{array}$ & 550 & 503 & 555 & 521 & 573 & 524 & 575 & 537 & 586 & 561 \\
\hline
\end{tabular}

\section{Our plans}

\subsection{List measures}

According to the 3 E's of sustainability we have listed six measures, as follows:

Table 2. Corresponding measures

\begin{tabular}{l|l}
\hline \multirow{2}{*}{ Economically prosperous } & (c1) Attract investment \\
\cline { 2 - 2 } & (c2) Promote employment \\
\hline \multirow{2}{*}{ socially Equitable } & (c3) Promote consumption \\
\cline { 2 - 2 } & (c4) By the city green area \\
\hline \multirow{2}{*}{ Environmentally Sustainable } & (c5) Prevent the spread of the city \\
\cline { 2 - 2 } & (c6) Raise the minimum wage \\
\hline
\end{tabular}

4.2 Definition of potential value

We believe that the potential of each plan is related to the weight of each measure, but it is also related to the current state of development of each of the measures' counterparts. If a higher level of this factor would hinder the plan, we define the expression of the potential value as:

$$
\mathrm{S}=\frac{w}{j}
$$

In the expression, $w$ is the weight. $j$ is the current level of development of the factor. We define the current level of development

among them, $\bar{x}=\frac{1}{n} \sum_{i=1}^{n} x_{i}, s_{j}=\frac{1}{n-1} \Sigma\left(x_{i j}-u_{j}\right)^{2}$

$$
j_{i}=1 \pm\left(\frac{x_{1=2015}-\bar{x}}{s}\right)
$$

In this expression, $x_{1=2015}$ represents the date of the factor $i$ in 2015. If the higher the valu e of the factor,

the higher the level of development, we use '+';if the smaller the value of the factor, the $h$ igher level of development, we use'-'.

For the urban area growth factor, we define the current level of urban area growth as $H$, the expression is:

$$
H=\frac{1}{1+10 Q}
$$

So we can get two cities of the current development of the value of the table:

Table 3. A table about current development values

\begin{tabular}{|l|c|c|c|c|c|c|}
\hline factor & $\mathrm{X} 1$ & $\mathrm{X} 3$ & $\mathrm{X} 4$ & $\mathrm{X} 5$ & $\mathrm{X} 6$ & $\mathrm{H}$ \\
\hline measures & $\mathrm{C} 1$ & $\mathrm{C} 4$ & $\mathrm{C} 6$ & $\mathrm{C} 2$ & $\mathrm{C} 3$ & $\mathrm{C} 5$ \\
\hline $\mathrm{A}$ & 2.4426 & 0.8741 & 0.5978 & 2.8311 & 2.2678 & 0.8333 \\
\hline $\mathrm{B}$ & 1.2521 & 2.2119 & 1.6033 & 1.1782 & 1.6504 & 0.8 \\
\hline
\end{tabular}

4.3 Calculate the weight by AHP[3]

According to the 3 E's of sustainability, we get hierarchical chart 


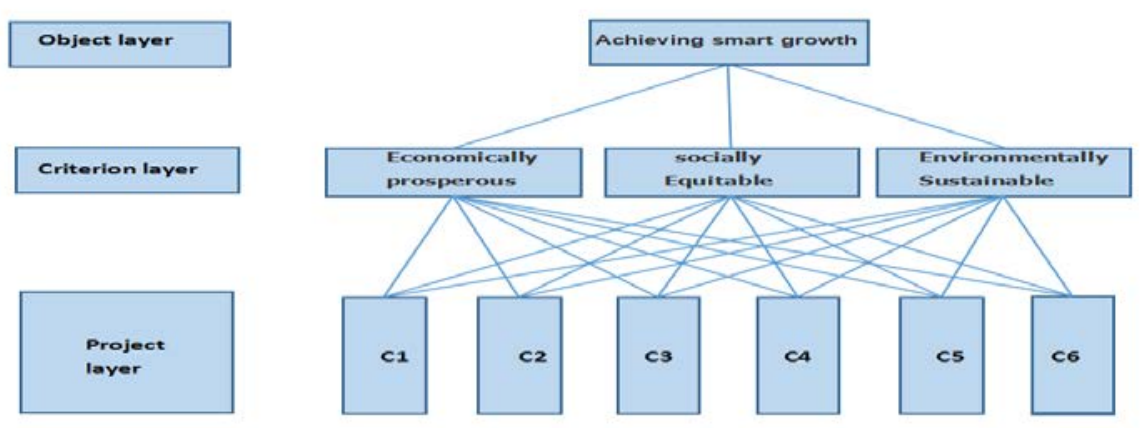

Fig 1. The structure of the AHP

We calculated the results by MATLAB, the results are in the following table:

Table 4.

\begin{tabular}{c|c|c|c|c|c|c|c|c|c}
\hline & $\lambda$ & $C I$ & $C R$ & \multicolumn{6}{|c}{$W$} \\
\hline$B 1$ & 6.1150 & 0.0230 & 0.0183 & 0.0370 & 0.2647 & 0.1237 & 0.1404 & 0.1116 & 0.3227 \\
\hline$B 2$ & 6.0391 & 0.0078 & 0.0062 & 0.2139 & 0.1215 & 0.1215 & 0.2542 & 0.2139 & 0.0749 \\
\hline$B 3$ & 6.5876 & 0.1175 & 0.0933 & 0.4348 & 0.2184 & 0.1600 & 0.1035 & 0.0507 & 0.0325 \\
\hline
\end{tabular}

From the above data to obtain the weight of each measure table:

Table 5 . The weight of various measures

\begin{tabular}{l|l|l|l|l}
\hline \multirow{2}{*}{ C B } & \multicolumn{1}{c|}{ society equal } & $\begin{array}{c}\text { Environmental } \\
\text { sustainability }\end{array}$ & $\begin{array}{c}\text { Economic } \\
\text { prosperity }\end{array}$ & \multirow{2}{*}{ The total weight } \\
\cline { 2 - 5 } & \multicolumn{1}{c|}{0.1283} & \multicolumn{1}{|c|}{0.2764} & 0.5954 & \\
\hline C1 Attract investment & 0.037 & 0.2139 & 0.4348 & 0.32274898 \\
\hline C2 Promote employment & 0.2647 & 0.1215 & 0.2184 & 0.19757897 \\
\hline C3 Promote consumption & 0.1237 & 0.1215 & 0.16 & 0.14471731 \\
\hline C4 Increase the green area & 0.1404 & 0.2542 & 0.1035 & 0.1498981 \\
\hline C5 Prevent the spread of the city & 0.1116 & 0.2139 & 0.0507 & 0.10362702 \\
\hline C6 Raise the minimum wage & 0.3227 & 0.0749 & 0.0325 & 0.08145527 \\
\hline
\end{tabular}

\subsection{Ranking of potential value}

Table 6 List of Potential value

\begin{tabular}{r|l|l|l|l|l|l|r}
\hline & C1 & C2 & C3 & C4 & C5 & C6 \\
\hline A & 0.1321 & 0.0698 & 0.0638 & 0.1715 & 0.1244 & 0.1363 \\
\hline B & 0.258 & 0.1677 & 0.0877 & 0.0678 & 0.1295 & 0.0508 \\
\hline
\end{tabular}

Thus we get the ranking of the measures of the two cities

Table 7 List of measures taken by the two cities

\begin{tabular}{l|l|l}
\hline & A & B \\
\hline 1 & C4 Increase the green area & C1 Attract investment \\
\hline 2 & C6 Raise the minimum wage & C2 Promote employment \\
\hline 3 & C1 Attract investment & C5 Prevent the spread of the city \\
\hline 5 & C5 Prevent the spread of the city & C3 Promote consumption \\
\hline 6 & C2 Promote employment & C4 Increase the green area \\
\hline
\end{tabular}

From the above table we can see for city A ,The most development potential of the measures is to increase the urban green area, and then to raise the minimum wage level, That means city A need to give priority to investing energy into the environment and social equity, while city B should give priority to energy to economic development. 


\section{Conclusions}

Smart growth has the function of judging the rationality of urban spatial expansion, and has the function of judging the scale, and has the sustainable guide effect to promote the expansion of urban space. [1]

In the process of building the model. When we define the potential value, we take into account the blocking effect of the current development of the various factors of the city on the measures. then we use Analytic Hierarchy Process.to improve the accuracy of the weight wo got. We conduct a potential value analysis of our plans and get the ranking of the measure potential values of the two cities. We also analyze the two cities should focus on the current direction of development.

\section{References}

[1] Luo Zhanfu. Based on the rapid growth of urban spatial expansion [D]. Northwest Normal University, 2009

[2] Cheng Maoji. Research on the evaluation and optimization of urban growth in Nanjing based on the perspective of smart growth. Diss. Nanjing Normal University, 2012

[3] Shoukui si. Mathematical Modeling Algorithms and Applications. National Defense Industry Press, 2015

[4] https://smartgrowthamerica.org/

[5] https://www.epa.gov/smartgrowth/smart-growth-publicatio 